\title{
GROUNDWATER OF OREL REGION AND FORECAST OF THEIR POLLUTION IN AREAS OF LIVESTOCK COMPLEX
}

\section{ПОДЗЕМНЫЕ ВОДЫ ОРЛОВСКОЙ ОБЛАСТИ И ПРОГНОЗ ИХ ЗАГРЯЗНЕНИЯ В РАЙОНЕ ЖИВОТНОВОДЧЕСКИХ КОМПЛЕКСОВ}

\author{
K. Seleznev, Post-graduate student \\ К.А. Селезнев, соискатель \\ N. Lysenko, Doctor of Agricultural Sciences \\ Н.Н. Лысенко, доктор сельскохозяйственных наук \\ S. Plygun, Candidate of Agricultural Sciences \\ С.А. Плыгун, кандидат сельскохозяйственных наук \\ Orel State Agrarian University, Orel City, Russia \\ Орловский государственный аграрный университет, г. Орёл, Россия \\ Phone: +7 (4862) 45-40-37, 45-40-59 \\ E-mail: monk_45-48@yandex.ru, n.lysenko@inbox.ru, borpli@rambler.ru
}

Received January 23, 2012

\begin{abstract}
In areas with intense economic activity showed a significant variety of forms of man-made ecological imbalance in the geological environment, as well as a manifestation of the natural geological environment of negative processes caused by groundwater. They give rise to environmental changes, both global and local scales. The degree of risk is determined to a large extent the processes taking place en masse in the geological environment, as a rule, have an inertial character and hidden from direct observation. For the first time for groundwater of Orel region is set by a previously unknown contaminant natural character due to the advancement of strontium in the groundwater complex, and is composed geofiltration model that allows to carry out prediction of the front of strontium in 27 years. Developed a model of the radial pull of nitrate intake group to establish the pathways of contaminant in water wells.
\end{abstract}

\begin{abstract}
АННОТАЦИЯ
В регионах с интенсивной хозяйственной деятельностью отмечается значительное многообразие форм техногенного нарушения экологического равновесия в геологической среде, а также проявление в геологической среде природных негативных процессов, обусловленных подземными водами. Они порождают изменения окружающей среды, как в глобальном, так и локальном масштабах. Степень риска при этом определяется в значительной мере процессами, массированно протекающими в геологической среде, как правило, имеющими инерционный характер и скрытыми от непосредственных наблюдений. Впервые для подземных вод Орловской области установлен ранее неизвестный загрязнитель природного характера, обусловленный продвижением стронция в водоносном задонско-оптуховского комплексе, и составлена геофильтрационная модель, позволяющая осуществить прогноз распространения фронта загрязнения стронцием на 27 лет. Разработана радиальная модель подтягивания нитратов групповым водозабором для установления пути попадания загрязнителя в водозаборные скважины.
\end{abstract}

\section{KEY WORDS}

Geofiltrational model; Underground waters; Strontium; Cattle-breeding complex; Pollution; Orel region.

\section{КЛЮЧЕВЫЕ СЛОВА}

Геофильтрационная модель; Подземные воды; Стронций; Животноводческий комплекс; Загрязнение; Орловская область. 
Орловская область имеет значительные ресурсы подземных вод, на которых базируется хозяйственно-питьевое и частично промышленное водоснабжение. По данным Комитета природных ресурсов Орловской области величина разведанных запасов на 01.01.2009 г. составляет 2590,7 тыс. м $^{3} /$ сут. Доля подземных вод в балансе хозяйственнопитьевого водоснабжения - $100 \%$.

Степень разведанности прогнозных ресурсов подземных вод по состоянию на 01.01.2011 г. составляет $29,8 \%$. На территории Орловской области разведано 55 месторождений и участков пресных подземных вод, запасы семи из них утверждены ГКЗ РФ в 2010 г.

В регионах с интенсивной хозяйственной деятельностью отмечается значительное многообразие форм техногенного нарушения экологического равновесия в геологической среде (загрязнение, включая целенаправленную закачку токсичных и радиоактивных стоков), а также проявление в геологической среде природных негативных процессов, обусловленных подземными водами, включая и катастрофические (оползневые, суффозионные, карстовые, процессы, связанные с многолетней мерзлотой и т.д.). Они порождают изменения окружающей среды, как в глобальном, так и локальном масштабах. Степень риска при этом определяется в значительной мере процессами, массированно протекающими в геологической среде, как правило, имеющими инерционный характер и скрытыми от непосредственных наблюдений.

В значительной степени влияют на качество подземных вод Орловской области животноводческие комплексы и миграция стронция в районе влияния стронциевой гидрогеохимической провинции.

Поэтому изучение условий формирования подземных вод и оценка геологической защищённости верхних водоносных горизонтов от загрязнения, а также выбор математического аппарата и разработка программного обеспечения расчётов движения загрязнённых вод в районе животноводческих комплексов являются весьма актуальными для регионов с интенсивной хозяйственной деятельностью человека и недостаточной защищенностью верхних водоносных горизонтов от загрязнения, каковым является Орловская область.

Исследования проводились в 2009-2011 гг. на базе ФГБОУ ВПО «Орловский государственный аграрный университет». Анализ проб осуществлялся в Инновационном научно-исследовательском испытательном центре ФГБОУ ВПО Орёл ГАУ. Работы по мониторингу животноводческих комплексов проводились по согласованию с ОАО «ГеоцентрМосква» - филиал «Геоцентр-Брянск», ТЦ «Орелгеомониторинг».

Таблица 1 - Крупные животноводческие комплексы Орловской области и объем образования ими отходов, 2009 г.

\begin{tabular}{|c|c|c|c|}
\hline Наименование животноводческого комплекса & $\begin{array}{l}\text { Мощность } \\
\text { (тыс. голов) }\end{array}$ & $\begin{array}{l}\text { Объем отходов } \\
\text { (тыс.т./год) }\end{array}$ & $\begin{array}{c}\text { Количество } \\
\text { скважин }\end{array}$ \\
\hline OAO A/Ф «Ливенское мясо» & 14,8 & 25,2 & 1 \\
\hline ООО «Знаменский СГЦ» (Троснянский р-н.) & 108 & 183,6 & 3 \\
\hline ЗАО «Славянское» & 0,5 & 3,8 & 1 \\
\hline ООО «Знаменский СГЦ» (Орловский р-н.) & 26 & 44,2 & 3 \\
\hline $\begin{array}{l}\text { ОАО АПК «Орловская Нива» Молочный комплекс СП } \\
\text { «Сабурово» }\end{array}$ & 2,2 & 16,5 & 1 \\
\hline $\begin{array}{l}\text { ОАО АПК «Орловская Нива» ООО «Фабрика по произ- } \\
\text { водству мяса птицы» }\end{array}$ & 505,8 & 17,0 & 1 \\
\hline ЗАО птицефабрика «Орловская» & 137,8 & 4,6 & 8 \\
\hline ОНО ОПХ «Стрелецкое» & 0,9 & 6,8 & 4 \\
\hline $\mathrm{A} / \Phi$ «Мценская» ПК «Мясо» & 0,5 & 3,8 & 1 \\
\hline ООО «Юпитер» & 1,2 & 9 & 2 \\
\hline ООО «Знаменский СГЦ» (Верховский р-н.) & 108 & 183,6 & 2 \\
\hline 3АO «Орелсельпром» & 108 & 183,6 & 3 \\
\hline
\end{tabular}

Анализируя крупные животноводческие комплексы, можно выделить 12 предприятий с достаточным объемом образования отходов и имеющими лицензию на добычу подземных 
вод, либо получившие гидрогеологические заключения. Такое ограничение необходимо из-за отсутствия информации по геологотехнической конструкции скважин, а также по самому месту нахождения водозаборных скважин по множеству малых предприятий (уровень образования отходов которых не превышает 0,5-0,9 тыс.т./год) и вследствие этого невозможности продолжения исследования в качестве прогноза загрязнения и поиска генезиса загрязнителей.

Список объектов, соответствующих необходимым условиям, представлен в табл. 1. Информация о производительности животноводческих комплексов и объеме образования отходов предоставлена Департаментом сельского хозяйства Орловской области.

Для исследования использовался следующий алгоритм мониторинга: региональное опробование всех существующих скважин на водозаборах выбранных предприятий; ло- кальный отбор на водозаборах с установленными элементами, превышающими предельно допустимую концентрацию; повторный отбор установленных элементов, превышающих предельно допустимую концентрацию.

Локальные исследования проводились с ежегодной периодичностью. Отбор проводился согласно ГОСТ Р 51593-2000 «Вода питьевая. Отбор проб». Требования, предъявляемые к качеству питьевой воды, а также нормативные показатели (предельно допустимые концентрации) содержатся в СанПиН 2.1.4.107401 «Вода питьевая. Гигиенические требования к качеству воды централизированных систем питьевого водоснабжения. Контроль качества».

Проведенный мониторинг водозаборов сельскохозяйственных предприятий выявил химические компоненты, превышающие ПДК (табл. 2).

Таблица 2 - Состояние водозаборов животноводческих предприятий Орловской области

\begin{tabular}{|c|c|c|c|c|}
\hline Название предприятия & Загрязнитель & $\begin{array}{l}\text { Значение } \\
\text { мкгцдм }\end{array}$ & ПДК мкгцдм ${ }^{3}$ & Превышение, раз. \\
\hline \multirow{3}{*}{ ЗАО «Орелсельпром» } & $\mathrm{Sr}^{2+}$ & 34000 & 7000 & 4,8 \\
\hline & $\mathrm{Sr}^{2+}$ & 15000 & 7000 & 2,14 \\
\hline & $\mathrm{Sr}^{2+}$ & 8600 & 7000 & 1,23 \\
\hline д. Брагино & $\mathrm{Sr}^{2+}$ & 10000 & 7000 & 1,43 \\
\hline \multirow{5}{*}{ ЗАО птицефабрика «Орловская» } & $\mathrm{NO}_{3}^{-}$ & 51,29 & 45,0 & 1,14 \\
\hline & $\mathrm{NO}_{3}^{-}$ & 63,79 & 45,0 & 1,42 \\
\hline & $\mathrm{Fe}_{\text {обше. }}$ & 0,77 & 0,3 & 2,57 \\
\hline & $\mathrm{Fe}_{\text {об뜨. }}$ & 3,19 & 0,3 & 10,63 \\
\hline & $\mathrm{Fe}_{\text {общ. }}$ & 0,61 & 0,3 & 2,04 \\
\hline
\end{tabular}

Для сравнения соседние Тульская и Калужская области имеет большие площади влияния стронциевой провинции и гораздо более высокие концентрации (рис. 1). До 2009 года (к началу настоящего исследования) изза недостаточной изученности влияние стронциевой провинции обнаружено не было, и высокие содержания стронция на территории Орловской области не фиксировались.

Основными используемыми водоносными комплексами согласно разрезу являются плавский и задонско-оптуховский (рис. 2).

Водоносный плавский карбонатный комплекс(D3pl) распространён повсеместно. Водовмещающими породами служат серые трещиноватые, иногда закарстованные плитчатые доломиты мощностью до 65 м. Воды безнапорные. Питание комплекса осуществляется за счёт атмосферных осадков и перетока из вышележащих водоносных горизонтов, разгрузка - в современную овражно-балочную сеть. Водоносный комплекс изучен слабо, используется для водоснабжения совместно с задонско-оптуховским комплексом.

Водоносный задонско-оптуховский карбонатный комплекс (D3 zd-op) также распространён повсеместно. Водовмещающая толща сложена неравномерно трещиноватыми, а верхней части иногда закарстованными светло-серыми известняками мощностью 100-132 м. Трещиноватость и закарстованность карбонатных пород с глубиной резко уменьшается. В пойменных частях рек и ручьёв водоупорная кровля практически отсутствует. На водоразделах и их склонах этот комплекс перекрывается глинистыми известняками и мергелями (киселёво-никольского водоупора D3ksn). 


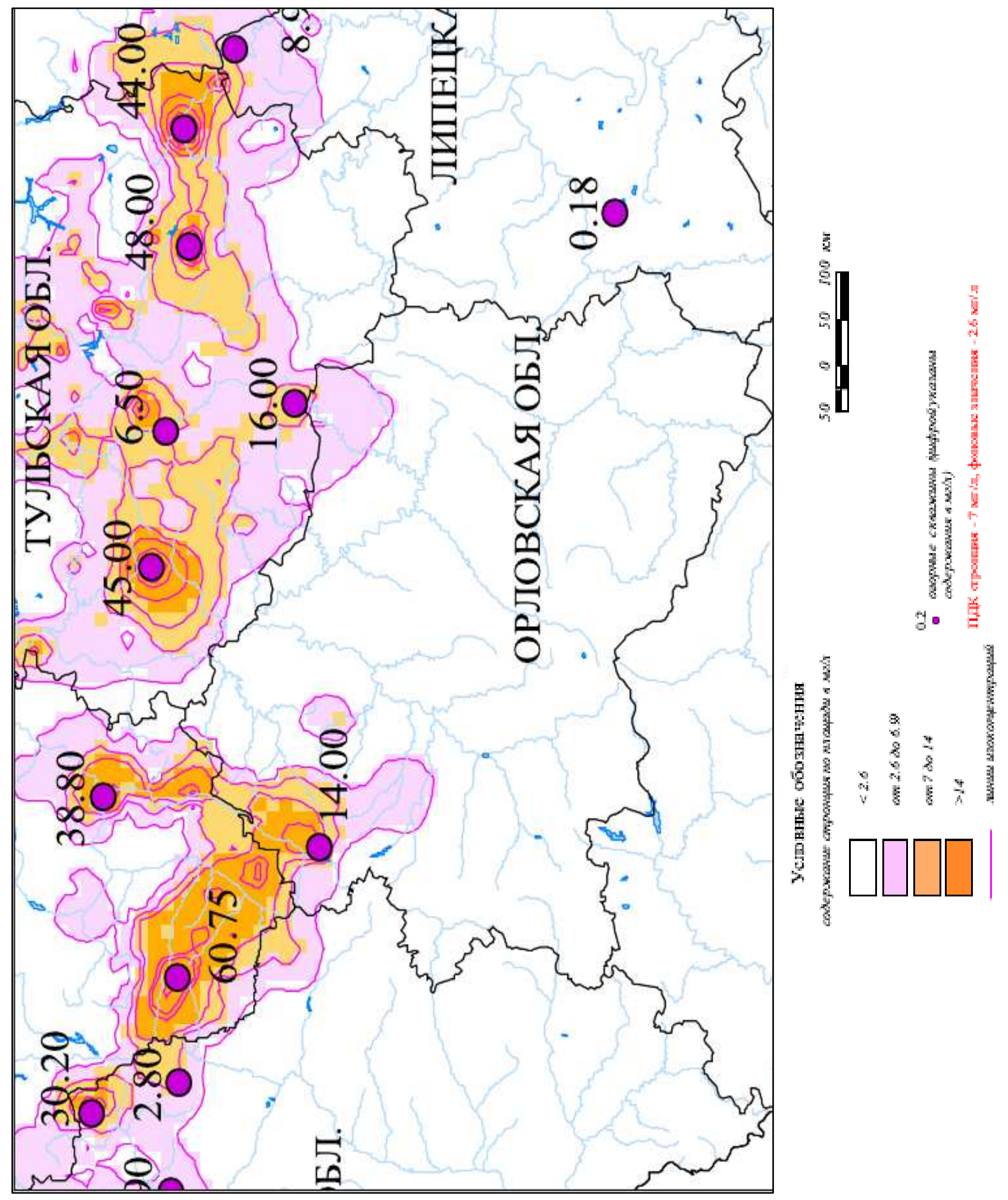

Рисунок 1 - Влияние стронциевой провинции на качество подземных вод в пределах Орловской области (по данным ОАО «Геоцентр-Москва») 
Водоупорным ложем служат плотные разности глинистых известняков и глин задонского горизонта (D3 zd) мощностью до 12 метров. Подошва и мощность горизонта устанавливались по скважине № 54200027 (номер согласно ГВК) глубиной 614 метров, с учетом падения 2,14 м на 1 км в сторону скважины
54200027 (расчеты проводились по аналогии с подошвой лебедянского горизонта).

Водоносный комплекс вскрыт и опробован в районе исследования многими эксплуатационными, разведочными и наблюдательными скважинами. Воды комплекса безнапорные. Коэффициент фильтрации изменяется от 1 до 15 м/сутки.

A

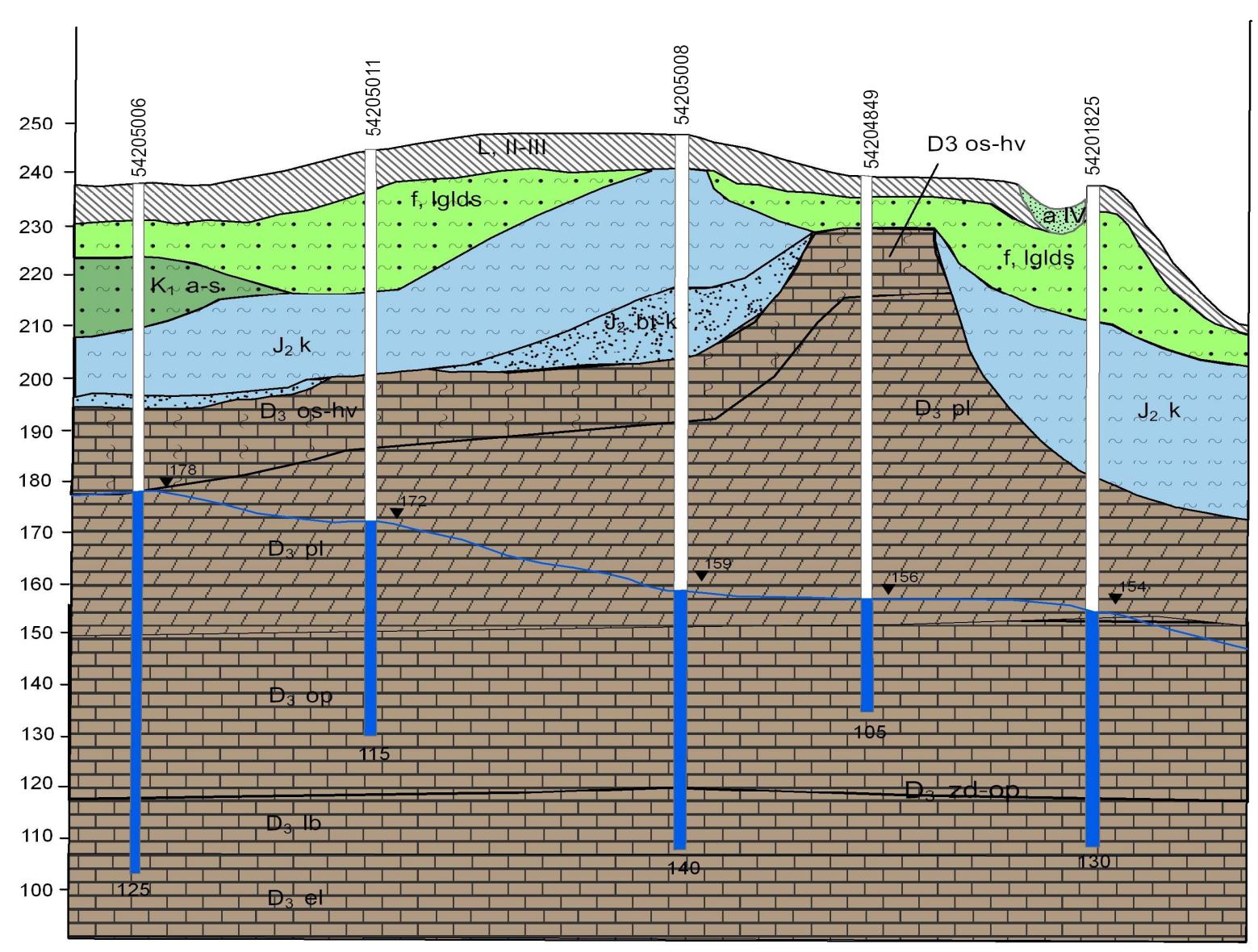

Рисунок 2 - Гидрогеологический разрез в районе водозабора ЗАО «Орелсельпром»

Согласно проведенным расчетам, продвижение фронта стронциевой провинции через 10000 суток (27 лет) составит 1058 метров. Результаты расчета для геофильтрационной модели с шагом 500 на 500 метров (рис.3) представлены в табл. 3.

Оценка влияния диффузии на движение границы раздела стронциевых вод и вод в кондиционном состоянии проводилась согласно В.М. Шестакову. Прохождение при расчетной скорости без учета дисперсии будет равно 1058 метра. В итоге при разных параметрах $\mathrm{D}_{0}$ размах дисперсии будет составлять от 0,5 до $3,8 \%$. Следовательно, ошибка в оценке расстояния перемещения стронциевой границы будет незначительной.

Практическим аспектом разработки проблематики исследования загрязнения подземных вод явилось создание компьютерной программы для ЭВМ «Filter Complex v1.0 - расчет массопереноса в почвенном и водоносных горизонтах в условиях сельскохозяйственного производства в вертикальном и горизонтальном (латеральном) направлениях», которая позволяет существенно оптимизировать расчеты при моделировании движения подземных вод. 
В основу программы заложены использованные в настоящей работе математические модели. «Filter Complex v1.0» (свидетельство о государственной регистрации программ ЭВМ №2011614248). Структурно она состоит из двух частей:

- «RFilter v1.0 - расчёт фильтрации загрязнителей почвенного и водоносных горизонтов» (свидетельство о государственной регистрации программ ЭВМ №2011613400);

- «MFilter v1.0 - расчет массопереноса в почвенном и водоносных горизонтах в условиях сельскохозяйственного производства» (свидетельство о государственной регистрации программ ЭВМ №2011613401).

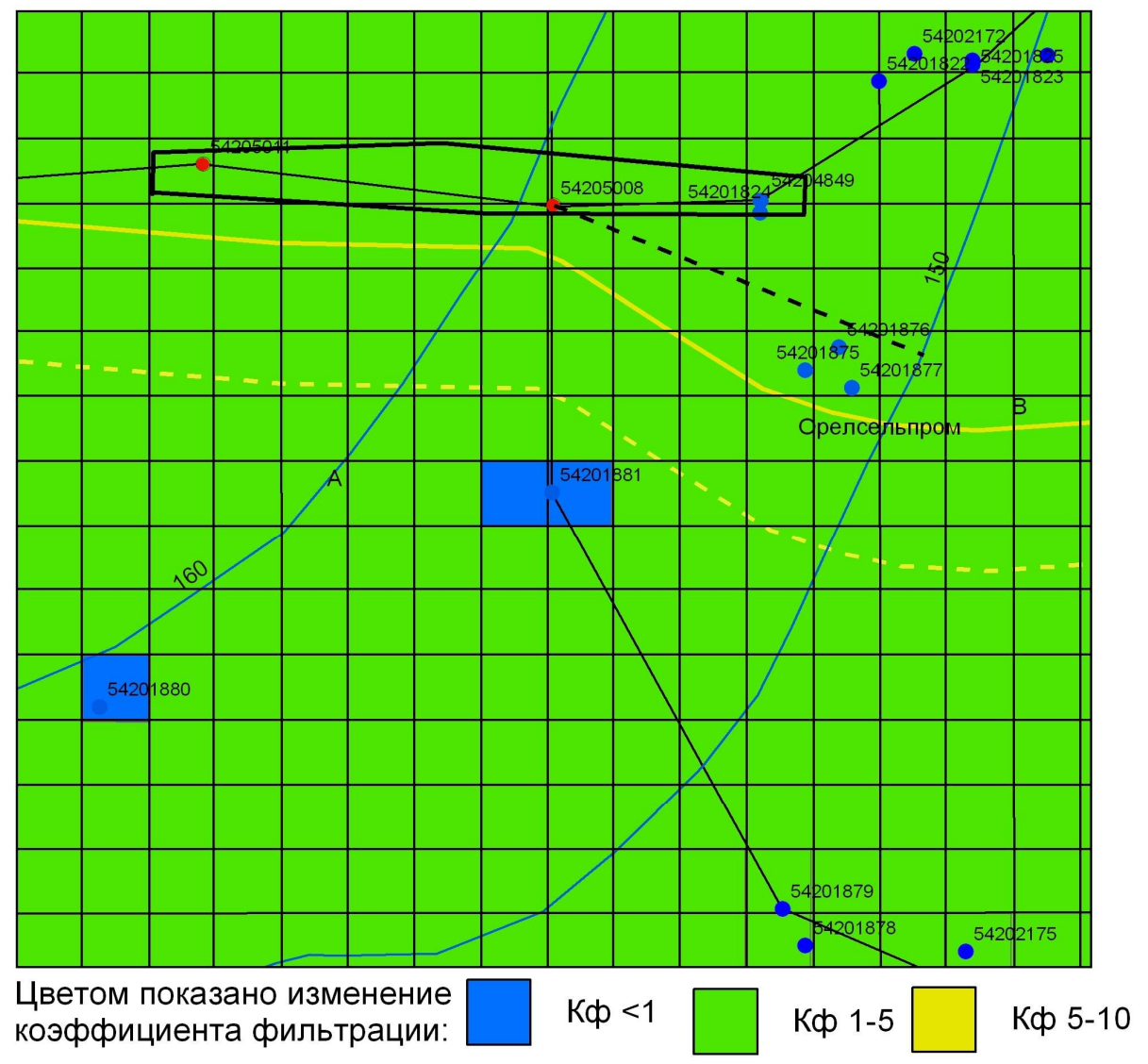

Рисунок 3 - Геофильтрационная модель с прогнозируемым продвижением стронциевого фронта через $10^{4}$ суток

Таблица 3 - Результаты расчетов для задействованных скважин

\begin{tabular}{|c|c|c|c|c|c|c|c|}
\hline Гвк & $\mathrm{Q}, \mathrm{M}^{3} / \mathrm{cyT}$ & $\mathrm{Rn}, \mathrm{M}$ & $\mathrm{r}_{0}, \mathrm{M}$ & $\mathrm{H}, \mathrm{M}$ & $\mathrm{S}_{0}, \mathrm{M}$ & $\xi$ & $\mathrm{K} \phi, \mathrm{M} / \mathrm{cyT}$ \\
\hline 54201181 & 86,40 & 1000 & 0,12 & 66,00 & 24,20 & 4,01 & 0,1 \\
\hline 54201880 & 190,00 & 1000 & 0,15 & 87,00 & 18,00 & 21,80 & 0,4 \\
\hline 54201879 & 240,00 & 1000 & 0,08 & 68,00 & 5,00 & 24,90 & 2,5 \\
\hline 54201878 & 167,60 & 1000 & 0,12 & 70,00 & 4,00 & 9,64 & 1,4 \\
\hline 54202175 & 259,20 & 1000 & 0,08 & 56,00 & 3,00 & 4,01 & 2,9 \\
\hline 54202176 & 720,00 & 1000 & 0,15 & 64,00 & 2,00 & 4,01 & 9,8 \\
\hline 54202177 & 360,00 & 1000 & 0,08 & 65,00 & 3,00 & 11,00 & 4,5 \\
\hline 54201889 & 216,00 & 1000 & 0,16 & 62,00 & 10,00 & 964,00 & 29,5 \\
\hline 54201888 & 172,80 & 1000 & 0,08 & 58,00 & 10,00 & 24,90 & 1,1 \\
\hline 54202173 & 120,00 & 1000 & 0,12 & 60,00 & 2,00 & 21,80 & 3,2 \\
\hline 54205006 & 285,12 & 1000 & 0,10 & 106,00 & 3,00 & 24,90 & 3,1 \\
\hline 54205008 & 362,88 & 1000 & 0,10 & 87,00 & 5,00 & 24,90 & 2,9 \\
\hline 54205011 & 480,00 & 1000 & 0,10 & 100,00 & 2,00 & 79,60 & 18,8 \\
\hline
\end{tabular}


Применение программного комплекса оптимизировало процесс расчетной части в 2 раза, что сократило время вычислений до 0,25 чел./день, и общее отведенное время на этот вид работы снизилось до 3,60 чел./день (1 категория сложности) и 7,79 чел./день (2 категория сложности). Это позволило более рационально и эффективно распределять рабочее время. Распределение времени дает экономический эффект в виде экономии денежных средств: при расчетах зон санитарной охраны 1 категории сложности на 1373 рубля и 2 категории сложности на 1833 рубля. Затраты времени на проектирование взяты по аналогии с проектом на выполнение работ по объекту «Ведение государственного мониторинга состояния недр на территории ЦФО».

Основываясь на анализе гидрогеохимической обстановки и данных, полученных в результате настоящего исследования, можно предложить следующие рекомендации производству:

1. Для водоснабжения размещенного производства в зоне влияния стронциевой провинции, использовать мощности локально залегающего плавского горизонта (D3pl), предварительно оценив запасы пресных подземных вод, а также использовать водоносные горизонты, залегающие выше задонскогооптуховского комплекса (D3zd-op). Приблизительные высоты простирания кровли которого по Балтийской системе в районе водозабора ОАО «Орелсельпром» составляют $150 \mathrm{M}$.

2. При выборе места строительства производственных комплексов следует учитывать зону влияния стронциевой провинции, а также необходимо проводить гидрогеологические работы с применением бурения для более детального определения местоположения и динамики стронциевого загрязнения.

3. Для дальнейшего функционирования водозабора ЗАО «Орловская птицефабрика» необходимо провести переоборудование очистных систем и использовать в дальнейшем более современное оборудование для водоподготовки, чтобы исключить влияние подтягивания некондиционных вод в эксплуатируемый водозабор для водоснабжения в хозяйственно-питьевых целях.

\section{БИБЛИОГРАФИЯ}

Beck, L. A review of farm waste pollution / L. Beck. J.Inst. Water and En $\neg$ viron. Manag. -1989. - Vol.3. № 5. - P.467-477.

Bel, O. Nitrate pollution of groundwater in Western Europe. / O. Bel, W.H.M. Duynisveld, J. Boettcher //Agricult.Ecol. Invest. Environ. -1989. -Vol.26.-P.189-214.

Evaluation of potential geologic sources of nitrate cjntamination in ground water. Cedar Valley, Iron Country, Utah with emphasis on the Enoch area / UGS Spec Stady. 2001, 100/c/i, iii-v, 117 pp.

Hafner, M. Wasser ist kein Naturprodukt mehr / Natur. (BRD).-1989. - № 10. - S.20-24.

Headworth, H.G. Contamination of groundwaters from diffuse sources arising from farming activities / H.G. Headworth //J.Inst. Water, and Environ. Manag. 1989. - Vol.3, № 5. - P.517-521.

Holting B. Konzept zur Ermittung der Schutzfunrtion der Grundwasseruber-deckung / B. Holting // Geologisches Jahrbuch, Reihe C, Heft 63, Hannover, 1995.

Howard, K. W. F. and Mullings, E. (1996).
Hydrochemical Analysis of GroundWater Flow and Saline Intrusion in the Clarendon Basin / Howard, K. W. F. and Mullings, E. // Groundwater - Jamaica. 1996, p 34(5);

Impact of nitrate poiltion sources on groundwateer quality - some examples from Czechoslovakia /V.Benes, V.Pckny, J.Skepa, J.Vrba // Environ, health perspect. - 1989. - № 83. - P.5-24.

Kato, H. Nitrate nitrogen in ground waters in the Kitatama area of Tokyo./ H. Kato, N. Ogura // Japan J. Limnol., 1992. - Vol.53. - P.265-248.

Lewis, B.G. Release of Radon-222 by vascular plants; effects of transpiration and leaf area / B.G. Lewis B.G, M.M. MacDonell // Environ. Qual. 19. 1990. P. 93-97.

McDonald, M.G. MODFLOW, A Modular Three-Dimensional Finite Difference Groundwater Flow Model / M.G. McDonald, A.W. Harbaugh // U.S. Geological Survey Open File Report 83 - Washington, DC. 1988. - 875, Chapter 1. 
Paulsen, S.G. The role of watersheds in the probability design of the Environmental Monitoring and Assesment programme (EMAP) / S.G. Paulsen //Ecos. -1992. Vol.73, № 43, Suppl.- P.179.

Pearson, J. Soil concentration of emanating radium-226 and emanation of radon-222 from soil and plants / J. Pearson, E. Jones // Tellus 18. 1966. P. 655 - 662.

Poent, M.F. Urban wastewater treatment by electrocoagulation and flotation / M.F. Poent, A. Grasmick // Water science and technology. 1995. - № 31 (3). -P. 275-283

Pohle, W. Wassergevinnung und Naturschutz in der Nord-heide / W. Pohle Neue DELIWA-Z. - 1989. - Vol.4O, № 5.S.224-228.

Policy and practice for protection of groundwater. L: Environment Agency of U.K., 1998. $57 \mathrm{p}$.

Ruchay, D. Pflanzenschutzmittelanwendung ohne Grundund Trinkwassergefahrdung Aspekte des Umweltschutzes //Schriftenr. Ver. Was- ser, Boden und LuShilo M. Strategies of adaptation to extreme conditions in aquatic microorganisms. Naturwissenschaften, 1980, 67, 8, pp 348389. fthyg. -1989. - № 79. - S.39-44.

Sato, K. A study on environmental externalities of agriculture and its cost allocation problem / K. Sato // Mem. Graduate School Agr. Hokkaido Univ. -2000.Vol.23.-№2.- p. 61-118.

Savane, I. Groundwater survey methodology in crystalline basement areas; example of district of Korhogo / I. Savane, K. Affian // Engineering geology, №44, 1991. P. 79-89.
Shilo, M. Strategies of adaptation to extreme conditions in aquatic microorganisms / M. Shilo // Naturwissenschaften, 1980, 67, 8, pp. 348 - 389.

Smyth I. D., Istok I. D. Multivariat geostatistical analisis of groundwater Contamination by pesticide and nitrate: a case history./ I. D.,Smyth, I. D. Istok // Geostatistics, 1990, vol.2., - p. 713-724.

Sources of nitrogen in groundwaters near Fairbanks // Northwa-ter. -1987. - № 34. P.2-4.

Travis, C.C. Superfound: a program without priorities / C.C. Travis, C.B. Dory //Environ. Sci. and Technol. -1989. Vol.23. - № 11. - P.1333-1334

Venbure, L.C. Monitoring the effect of surface mining operations on the 1. www.hydrologic regim / L.C. Venbure // Ground Water Monitor. Rev. 1983. Vol.3, № 1. P.86-91.

Vrba, J. Guidebook on mapping groundwater vulnerability / J. Vrba, A . Zaporozec Hannover, 1994. 131 p.

Yilmaz, I. Geotechnical properties of alluvial soils: an example from South of Sivas, Turkey / I. Yilmaz // Engineering geology, №55, 1997. P. 159-167.

Zimmerman, D. A., et al., A comparison of seven geostatistically based inverse approaches to estimate transmissivities for modeling advective transport by groundwater flow, Water Resour. / D.A. Zimmerman - Res., 34(6), 1998. P. 13731413. 